\title{
Reflectance Transformation Imaging Systems for Ancient Documentary Artefacts
}

\author{
Graeme Earl \\ University of Southampton \\ Archaeological Computing \\ Research Group \\ Southampton SO17 1BF \\ graeme.earl@soton.ac.uk
}

Charles Crowther

University of Oxford

Faculty of Classics

Oxford OX1 3LU

Eleni Kotoula

University of Southampton

Archaeological Computing

Research Group

Southampton SO17 1BF

\author{
Philip Basford \\ University of Southampton \\ Electronics and Computer \\ Science \\ Southampton SO17 1BJ
}

Jacob Dahl

University of Oxford

Faculty of Oriental Studies

Oxford OX12LE

Kirk Martinez

University of Southampton

Electronics and Computer

Science

Southampton SO17 1BJ

\author{
Alexander Bischoff \\ University of Southampton \\ Electronics and Computer \\ Science \\ Southampton SO17 1BJ
}

Michael Hodgson

University of Southampton

Electronics and Computer Science

Southampton SO17 1BJ

Hembo Pagi

University of Southampton

Archaeological Computing

Research Group

Southampton SO17 1BF

\author{
Alan Bowman \\ University of Oxford \\ Faculty of Classics \\ Oxford OX1 3LU
}

Leif Isaksen University of Southampton Archaeological Computing Research Group Southampton SO17 1BF
Kathryn E. Piquette
University of Oxford
Faculty of Classics
Oxford OX1 3LU

\begin{abstract}
This paper discusses the interim results of the AHRC RTISAD project. The project has developed and tested a range of techniques for gathering and processing reflectance transformation imaging (RTI) data. It has also assembled a detailed understanding of the breadth of RTI practice. Over the past decade the range of applications and algorithms in the broad domain of RTI has increased markedly, with current working addressing issues such as large resolution capture, 3D RTI, annotation, enhancement amongst others. Capture of RTI datasets has begun to occur in all aspects of cultural heritage and elsewhere. This has in turn prompted the development of policies and methods for managing and integrating the large quantities of data produced. The paper describes these techniques and issues in the context of a range of artefacts, including painted Roman and Neolithic surfaces, examples of ancient documents in a variety of forms, and archaeological datasets from Herculaneum, Çatalhöyük, Abydos and elsewhere. The paper also identifies on-going software development work of value to the broad EVA community and proposes further enhancements.
\end{abstract}

RTI. PTM. HSH. Imaging. Archaeology. Ancient documents. Conservation.

\section{INTRODUCTION}

The Reflectance Transformation Imaging Systems for Ancient Documentary Artefacts project was funded by the UK Arts and Humanities Research Council in 2010 via the Digital Equipment and Database Enhancement for Impact (DEDEFI) scheme. Reflectance Transformation Imaging (RTI) describes a suite of technologies and methods for generating surface reflectance information using photometric stereo i.e. by comparison between images with fixed camera and object locations but varying lighting (Woodham 1980). RTI now describes a file format (Mudge et al. 2006) in addition to a set of methods. The most common implementation of RTI is via Polynomial Texture Mapping (PTM) invented by Tom Malzbender of HP
Labs in 2000 (Malzbender et al. 2000, 2001). Subsequent work has identified alternative approaches to compress defined surface properties including spherical and hemispherical harmonics (Mudge et al. 2008). Applications of PTM and other approaches to archaeological data have been trialled in a wide range of contexts (Earl et al. 2010a) and this project aimed to produce a broad understanding both of the state-of-the-art in RTI and its future potential, and the implications for its applications to ancient document and other archaeological data.

The aims of the Reflectance Transformation Imaging Systems for Ancient Documentary Artefacts project were as follows: 
(i) Produce two RTI capture systems

(ii) Create UK RTI capture and research hubs at Southampton and Oxford

(iii) Pilot capture of a range of ancient document artefacts

(iv) Pilot capture of a range of archaeological artefacts

(v) Integrate RTI into existing practices

(vi) Prototype an archaeology RTI repository

(vii) Disseminate widely for academic and public impact

Over the last year of research we have met all of these aims. Specifically, we have produced a number of dome-based capture systems and trialled novel technology provided by our partners at HP Labs. We have also established Southampton and Oxford as hubs for RTI research and implementation, including embedding RTI in the teaching and research activities in the host institutions and developing sustainable plans for long-term data capture and development. We have captured a broad representative sample of the ancient document and archaeological artefacts identified to be appropriate for RTI study. In addition we have developed and applied tools to embed RTI capture and processing in existing approaches, most notably in the context of annotation. We have developed a prototype repository for RTI data in collaboration with the Archaeology Data Service and Cultural Heritage Imaging (CHI) which is leading to further developments in the documentation and management of RTI datasets. Finally, we have undertaken widespread dissemination reaching academic, industrial, local and national government, the general public and other stakeholders all over the world.

\section{RTI CAPTURE TECHNOLOGIES}

The RTI literature includes many alternative capture approaches. These can loosely be divided into highlight and lighting rig systems. This project made extensive use of both types, and developed examples of each.

\subsection{Lighting rigs}

Fixed lighting rigs enable consistent capture of surface imaging data, with a fixed position and direction of light sources and means to calibrate colour variation between them. Lighting rigs have been developed in the form of arcs and arms, geodesic and hemispherical domes, and enclosing spheres. We developed a range of dome-based systems for this project, at varying radii. The radius of the dome defines the size of the object that can be captured to sufficient quality and also the types of lens needed and hence any distortion present.

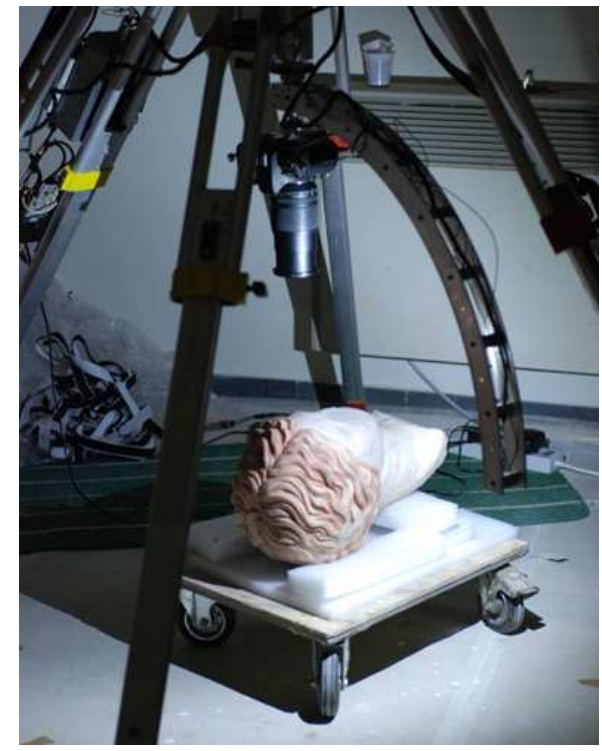

Figure 1: Robotic RTI arc in use at Herculaneum

The large format domes produced by the project are $1 \mathrm{~m}$ diameter and are made from plastic, divided into four quadrants for transportation. The size enabled high quality capture of the main size of target objects. Anything $17 \mathrm{~cm}$ across or smaller can be efficiently imaged, including small inscriptions, stylus and lead tablets, large cuneiform tablets and many archaeological objects such as stamped brick and amphorae. Each dome has 76 fixed LED light sources. The plastic dome is painted black, with a matte interior to minimise spurious illumination. The aperture at the top of the dome allows movement of the camera in order to generate pairs of data for photogrammetric processing.

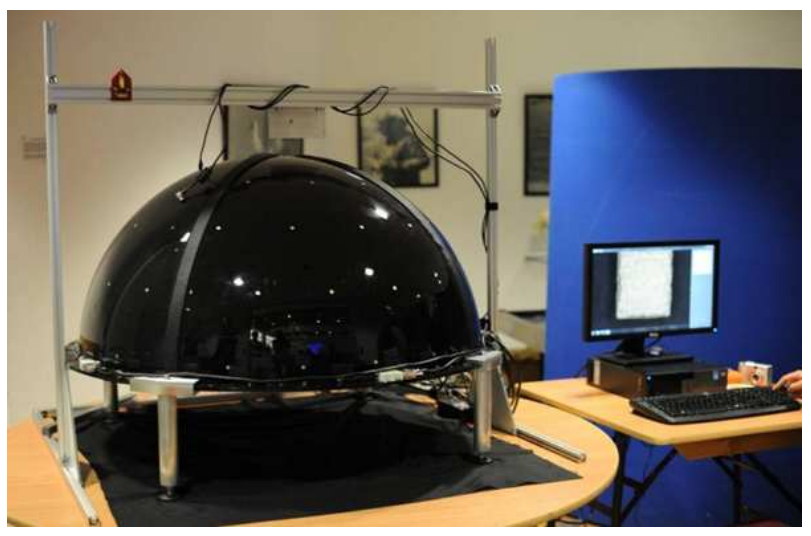

Figure 2: Dome capture system

The project uses Nikon D3X DSLR cameras. These provide $24.5 \mathrm{M}$ pixels with a 14 bit 35.9 by $24.0 \mathrm{~mm}$ FX CMOS sensor. The resulting images are $6048 \mathrm{x}$ 4032 pixels. The range of lenses employed includes $35 \mathrm{~mm}$, and $50 \mathrm{~mm}$ and $105 \mathrm{~mm}$ macros. We have seen no need to remove lens distortion as a standard processing step. However, we have 
identified suitable batch processing tools to employ where necessary.

The dome lighting system has been trialled with several alternatives including Cree and Osram LEDs. The CREE XREWHT-L1-0000-008E7 produces 74 lumens while the Bridgelux BXRAN0402 produces 400 lumens which helps reduce exposure times. These produce a useful white light, have very fast on/off time, high consistency and negligible IR/UV emissions. A custom USBcontrolled switching unit and constant current source is driven using text commands from the capture software. Typical exposure was $0.25 \mathrm{~s}$ at F8 so objects are only illuminated for around 20 s.

There can be colour variations between some LEDs and their colour temperature is fairly low so we have developed a batch colour calibration workflow which produces SRGB. This uses the VIPS and NIP (Martinez and Cupitt 2005, Cupitt and Martinez 1996) open source image processing environments which produces easily repeatable processing workflows. In addition they provide an audit log of operations which could easily be fed into the RTI process metadata. We place a Macbeth colour calibration chart on the capture stage in order to generate a batch conversion colour calibration matrix for each light. Figure 3 shows the type of colour cast that is removed.
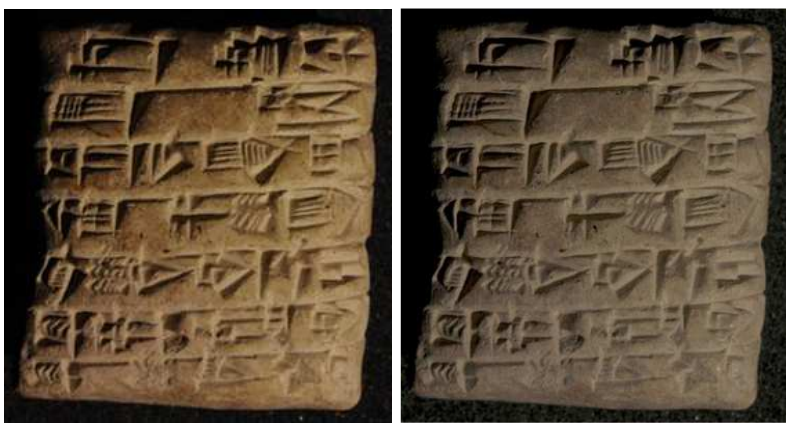

Figure 3: Original capture (left) and colour calibrated result (right)

One aim of the project was to produce a system that could be used continuously for large collections. As a consequence the dome system incorporates a scissor lift on a sliding platform which delivers the sample to the required location and height beneath the dome. In the current configuration the project captures a full set of images in c. 2 minutes, with an anticipated speedup as we introduce software optimisation in the final part of the project. Processing can then be accomplished alongside the next capture cycle, in advance of it, or in a batch process overnight. It is also possible to resample the captured images in order to produce a quick indication of the data quality.

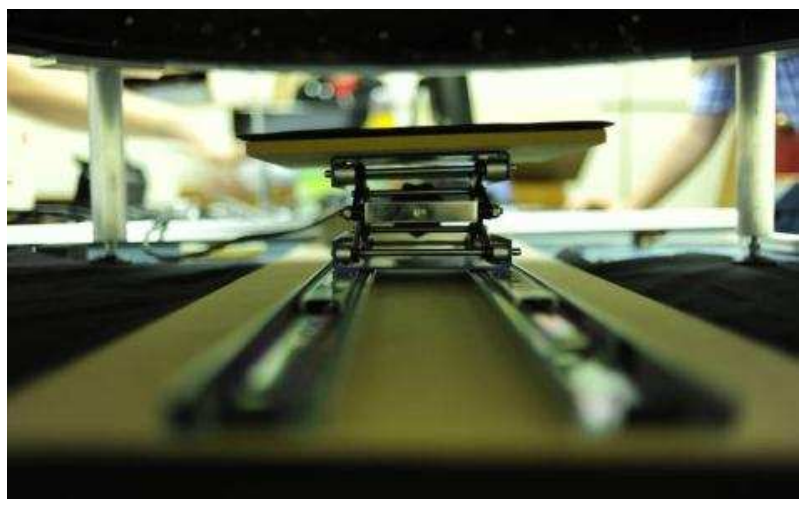

Figure 4: Example of delivery mechanism

A secondary aim was to produce a set of tools that were portable, and in particular that could be employed without prior planning for RTI capture. To this end we have experimented and further developed applications of the highlight RTI method (see below). In addition, we have developed a portable miniature RTI dome $25 \mathrm{~cm}$ in diameter that makes use of a smaller camera and requires only a netbook or similar device to power and manage its operation.

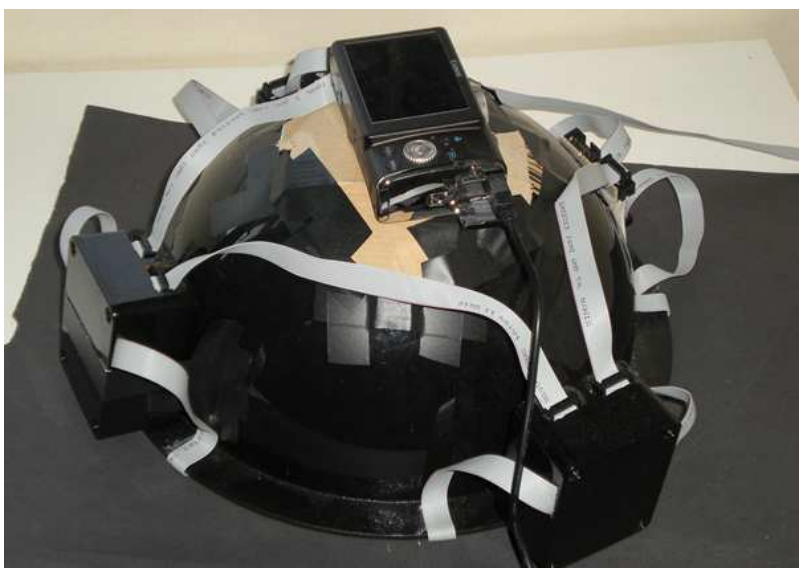

Figure 5: Prototype RTI mini dome

\subsection{Highlight systems}

The highlight RTI method enables rapid capture of data without a fixed lighting rig (Mudge et al. 2006). This project has used highlight in a range of contexts, including field capture of rock art and graffiti (Mudge et al. 2010), museum capture of small finds, and microscopic capture of conservation features.

The application of the technique to microscopic features has proved particularly exciting. The highlight RTI technique works in an identical fashion when using a microscope and small highlight target (such as a ball bearing). In one recent case study we imaged a ceramic roundel/ button from Tomb A at Derveni, Greece, located in the Archaeological Museum of Thessaloniki. It has a diameter $2.3 \mathrm{~cm}$ with remains of a red colour. The 
PTM enabled more detailed condition assessment, and in particular examination of craquelure, flaking and loss of red colour layer, salt efflorescence and depositions on the surface, as well as the rough ceramic texture.

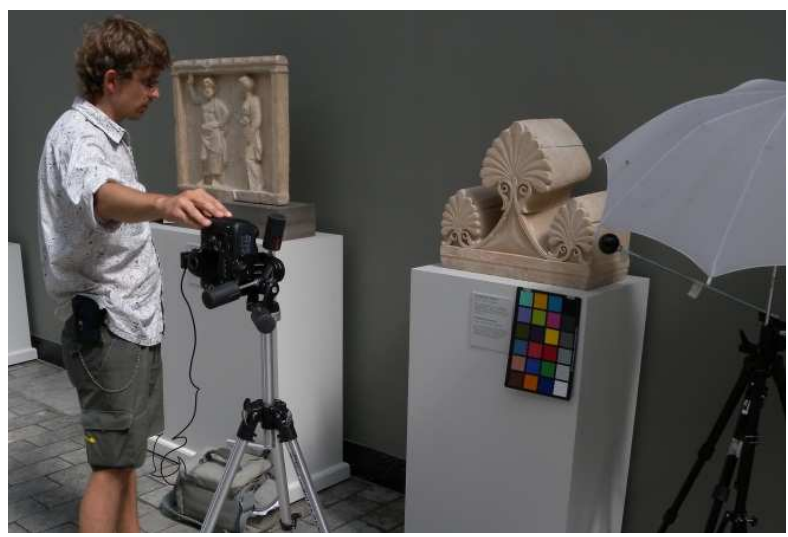

Figure 6: Highlight capture at Ny Carlsberg Glyptotek

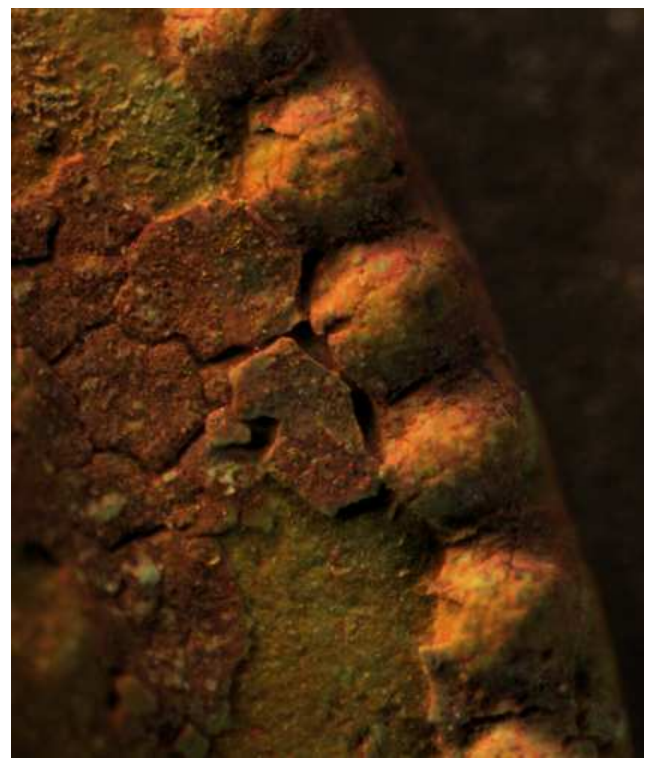

Figure 7: Microscopic highlight capture of ceramic roundel from Derveni, Tomb A, Greece (visible area is $0.3 \mathrm{~mm}$ across)

\section{RTI SOFTWARE}

\subsection{RTI processing}

The PTM approach was designed to provide a quick, light-weight compression of the reflectance and hence shape of imaged surfaces. The intention is not to produce accurate surface normals but rather (in terms of graphics) to produce enhanced surface simulation and (in terms of surface analysis) and intuitive means for exploring surface shape. There are a wide range of alternative methods for reconstructing more robust surface normal from similar input datasets (Drew et al. 2009). There have also been a number of metric analyses of PTM and comparisons to other forms of data acquisition (Dellepiane et al. 2006, Macdonald and Robson 2010).

However, in our experiments we have seen that the quality of data produced allows for useful comparison of surface normal (for example before and after conservation processing) and definition of significant surface deviations. We found that surface normal manipulation tools used in standard computer graphics pipelines work as efficient means to register and compare outputs.

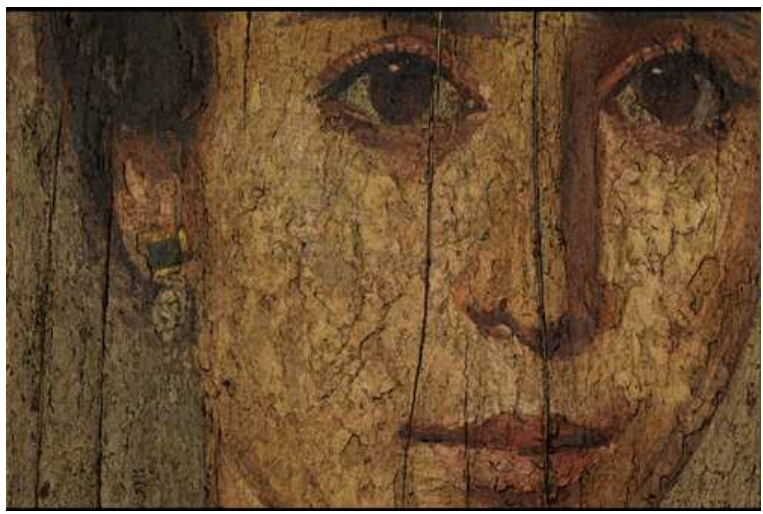

Figure 8: Surface normal contours at $1^{\circ}$ deviation for 160-170AD lime wood, gold and encaustic mummy portrait from Rubaiyat, Egypt (EA 65346 (C) Trustees of the British Museum)

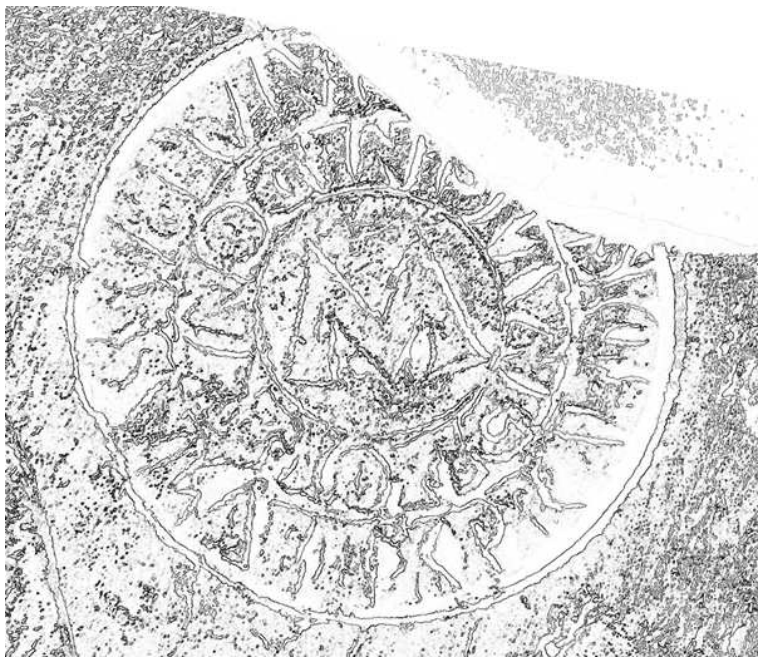

Figure 9: Sobel filter of output RTI normal data from Roman brick stamp (AHRC Portus Project)

The potential for RTI datasets as the input to nonphotorealistic rendering (NPR) was identified by Bartesaghi (et al. 2005). More recently TolerFranklin (et al. 2007) has demonstrated the broader potentials of NPR using red, green, blue, normal (RGBN) datasets. In our own work we have used surface normal contours to enhance painted surfaces and applied standard image processing tools such as sobel filters to enhance RTI data. It is clear from our applications that it would be very 
simple for conservation and other specialists to incorporate RTI image processing into their existing workflows, to considerable affect.

\subsection{RTI management}

In addition to the interpretation of RTI data the project has explored means to link interpretation to the data, to share these interpretations, and to manage the production of long-term repositories of RTI information.

Our extension to the newly updated RTI Viewer (RTIViewer) allows annotations to be created. These annotation boxes link to a textual description (and hence to external datasets) and also describe the viewer settings at the time the annotation was created. These bookmarks then enable the viewer to cycle through the annotations with the viewer updating to indicate the conditions under which the annotation was made, including the lighting direction. In this way it is possible to provide a nuanced representation of particular interpretations. As the annotations are stored as an external XML file they can be shared with others, combined, and re-imported to identify alternative readings.

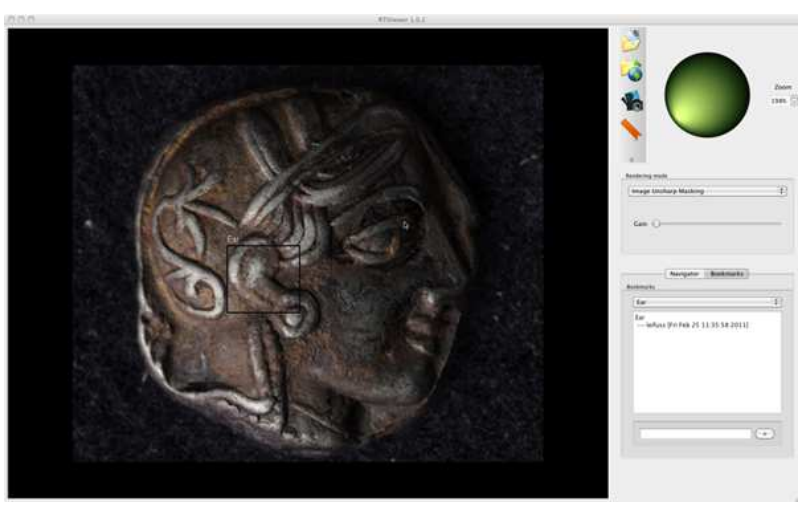

Figure 10: RTI viewer showing an annotation

The project has also considered the long-term sustainability of RTI datasets building on strategies identified by $\mathrm{CHI}$ (Mudge et al. 2008). A repository has been established hosted by the Archaeology Data Service which enables access to raw RTI input data, processed results, and metadata associated with their production. However, delivery of RTI data via the web remains problematic. The large file size has usually required down-sampling of RTI datasets for public dissemination. For the RTI repository we are taking advantage of two innovations. First, the RTI Viewer enables streaming of pyramidal datasets over the web. In addition the SpiderGL implementation of PTM (Di Benedetto et al. 2010) employs a different quadtree structure to enable rapid interaction with very large RTI datasets.

\section{RTI CAPTURES}

The project has attempted to trial RTI and to document its value on as wide a range of materials as possible.

Table 1: Summary of RTI captures to date

\begin{tabular}{|l|l|}
\hline \multicolumn{1}{|c|}{ Sample captures } & \multicolumn{1}{c|}{ Sample captures } \\
\hline amphora stamps & medieval metalwork \\
\hline brick stamps & Mosaics \\
\hline bronze bust & Paintings \\
\hline $\begin{array}{l}\text { carved architectural } \\
\text { stone }\end{array}$ & Pigment \\
\hline ceramics & $\begin{array}{l}\text { plaster (including } \\
\text { surfaces and decoration) }\end{array}$ \\
\hline clovis points & Porcelain \\
\hline Coins & $\begin{array}{l}\text { roman wood, lead and } \\
\text { selenite tablets }\end{array}$ \\
\hline cuneiform tablets & Seals \\
\hline excavated contexts & Squeezes \\
\hline $\begin{array}{l}\text { graffiti (including modern, } \\
\text { second world war, } \\
\text { medieval, roman) }\end{array}$ & stone sculpture \\
\hline Gravestones & tituli picti \\
\hline Handaxes & $\begin{array}{l}\text { tool and cut marks in } \\
\text { wood, bone and stone }\end{array}$ \\
\hline Inscriptions & wall paintings \\
\hline jade disc & $\begin{array}{l}\text { wood (including } \\
\text { waterlogged, PEG } \\
\text { treated, moulds, casts) }\end{array}$ \\
\hline medieval icons & \\
\hline
\end{tabular}

We will publish a separate evaluation of each of these applications in the future, including expert input from domain specialists. For this paper we provide a brief summary of the perceived value in two domains: cuneiform and Egyptian graphical culture.

\subsection{Cuneiform captures}

Cuneiform documents present a wide array of problems for traditional image capture. The inscribed objects are three dimensional; the inscribed surfaces are rarely flat, but most often convex; writing and non-writing marks may be found on any surface, often in multiple layers and directions; writing can be deeply or shallowly impressed; and the seal impressions often leave a very shallow relief of both text and image across text or below it. Furthermore, cuneiform texts are inscribed on both stone surfaces and objects made of clay or gypsum: the clay may be fired (mostly after discovery), and can be either matte or shiny. Earlier studies have demonstrated the utility of RTI on cuneiform and our intention has been to update these studies based on current capture methods and to undertake a detailed analysis of the utility of the techniques, and potential enhancements. 
From the viewpoint of the cuneiform specialist, the images produced in this study provide a considerable step forward in digital representation of cuneiform texts. First, the software conforms to standard practice and enables easy creation of an idealised snapshot of each tablet, using one or more lights perfectly to illustrate a given point. With online viewing software still in its infancy (see above) the Cuneiform Digital Library Initiative (CDLI) has opted for the export of such stills for online display of the images. However, our project's addition of annotation tools which can re-set any desired parameters further increases the potential of distributing the RTI data alongside such snapshots.

Cuneiform scholars are faced by very large collections of often decaying documents of which only roughly $20 \%$ of the total global holdings of probably in excess of a half million clay tablets and fragments have been published during the last 150 years of study. As a consequence our project took the pragmatic approach of employing a dual track capture process, using a flatbed scanner for regular surfaces and the RTI dome for unusual and difficult surfaces. Timings for this process were c. 5 minutes capture time using the flatbed scanner and c. 25 minutes using the RTI dome, capturing in both instances six surfaces of each object. This combined method appears to best suit the needs of cuneiform scholars. We anticipate that the method outlined by Brown et al. (2008) for obtaining RGBN data from a calibrated flatbed will very soon provide us with an efficient middle ground.

\subsection{Egyptology captures}

From an Egyptological perspective, in addition to improved readability for inscribed/ decorated objects, the value of RTI also lies in the detailed surface information provided through different RTI enhancement options. Close study of the RTI image of a perforated ivory with the aid of the specular enhancement and diffuse gain settings, has uncovered palimpsest and clarified marks relating to surface preparation and tool slips (Piquette forthcoming). The enhanced visibility RTI provides for such surface transformations, including information about tool use and technique, is of paramount importance for exploring material processes of script and image production and the reconstruction of past individual and collective practice.
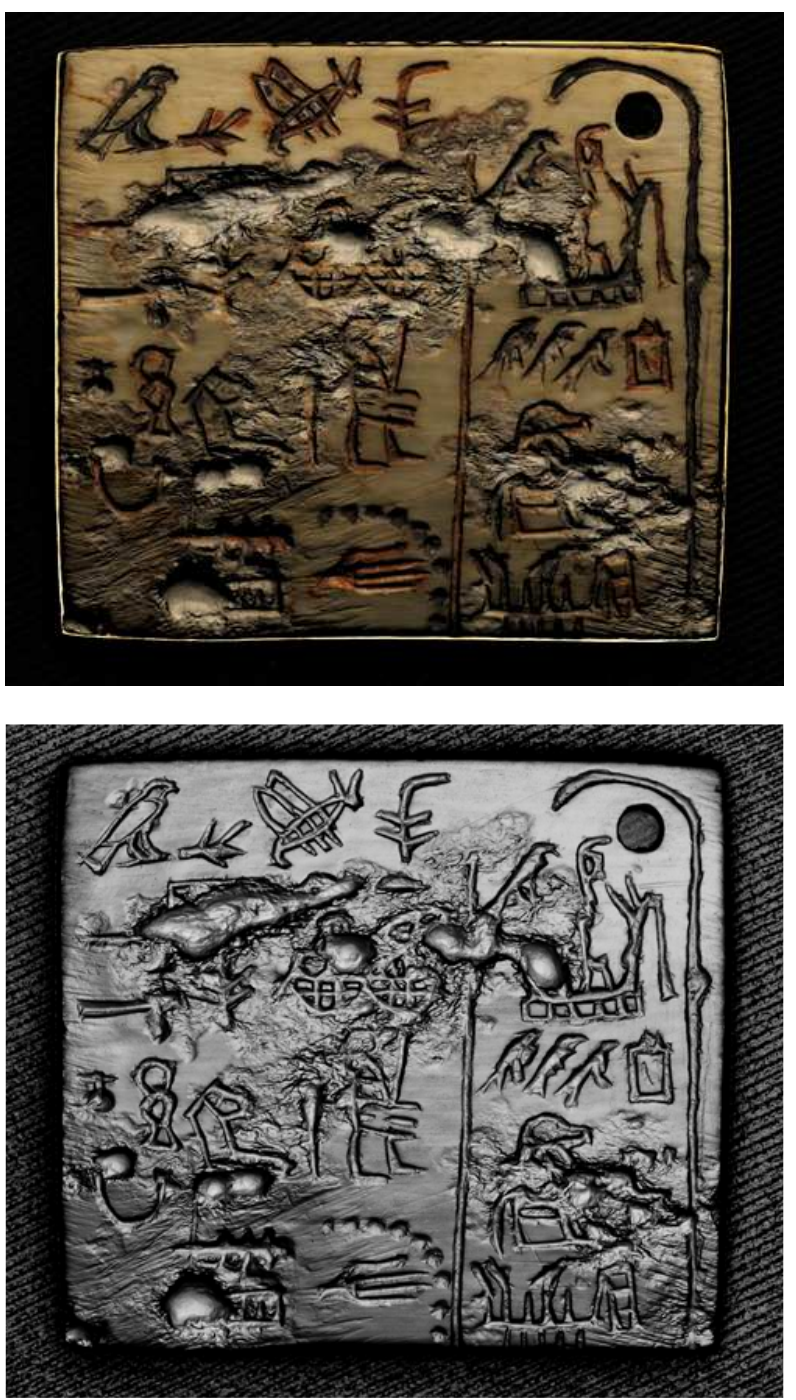

Figure 11: RTI detail of ivory funerary label showing erasure marks underlying incised signs in the lower left. Diffuse gain (top), specular enhancement (bottom). From Abydos, Egypt, c. 2700BC (EA 32668 (C) Trustees of the British Museum)

\section{GRAPHICS APPLICATIONS}

Elsewhere (Earl 2010b, 2009) we have demonstrated the possibilities of using RTI data in the construction of computer graphic simulations, in part through the creation of virtual PTMs. The potential of PTM for rendering was a prime motivation behind its development and enhancement (Hel-Or et al. 2003). During the current project we have concentrated on developing the use of diffuse and normal values from the captured RTI datasets to enhance simulations of the captured surfaces in novel environments. This has included the simulation of painted wall plaster at the site of Çatalhöyük in Turkey. 


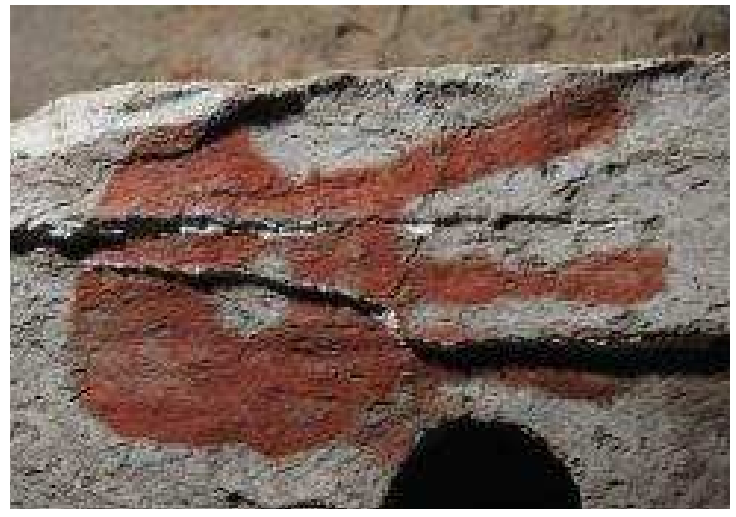

Figure 12: RTI capture of c. $8500 B P$ hand print from Çatalhöyük

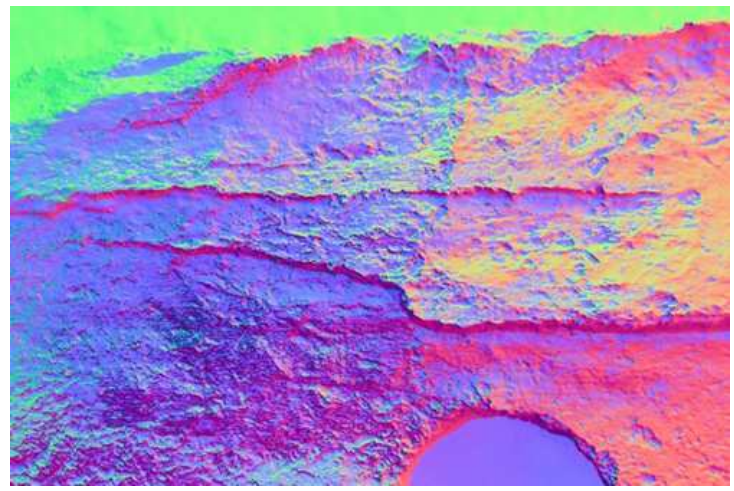

Figure 13: Surface normals of Çatalhöyük hand print shown in Figure 12

\section{DISSEMINATION}

In addition to the creation of digital representations the RTI data themselves have proven of value in communicating information about surface morphology to a wide audience. For example, at the Fitzwilliam Museum (Bridgman and Earl in press) we have been able to produce RTI captures that demonstrate the complex surface behaviour of lusterware ceramics, and in the future we will enhance this with $\mathrm{HSH}$ processing. Other dissemination has been via a range of conferences, workshops and lectures. These have included the Portable Antiquities Scheme, the IFA Finds Liaison Group, museum specialists, Archaeology and Classics students, English Heritage, the National Trust and the British Library (including demonstrations of the technology as part of the Growing Knowledge exhibition). Public dissemination has included articles in the Economist and British Archaeology, and a feature on a BBC history documentary.

\section{CONCLUSIONS AND FURTHER WORK}

The project has demonstrated the considerable potential of RTI in a wide range of subject domains pertaining to cultural heritage, and indeed more broadly. Our review of the state-of-the-art suggests a thriving research community characterised by a refreshing degree of collaboration and openness. It is our hope that future work further to enhance and integrate the technologies, and to undertake exhaustive and extensive captures will both lead to even greater awareness and democratisation of this suite of technologies.

\section{ACKNOWLEDGEMENTS}

The Reflectance Transformation Imaging Systems for Ancient Documentary Artefacts project was funded by the UK Arts and Humanities Research Council under the Digital Equipment and Database Enhancement for Impact (DEDEFI) scheme. Additional funding was provided by the AHRC Portus Project and by the Universities of Southampton and Oxford. We are grateful to the many institutions and individuals who have provided access to their collections and invaluable feedback. The examples shown in this paper were obtained in collaboration with the British Museum, the AHRC Portus Project, the Ashmolean Museum, the Archaeological Museum of Thessaloniki, the Ny Carlsberg Glyptotek, the Çatalhöyük project, and the Herculaneum Conservation Project. We are grateful to the project advisory board and in particular Tom Malzbender, Mark Mudge, Carla Schroer and Roberto Scopigno.

\section{REFERENCES}

Bartesaghi, A., Sapiro, G., Malzbender, T. and Gelb, D. (2005) Three-Dimensional Shape Rendering from Multiple Images. Graphical Models, Vol. 67, No. 4 (July).

Bridgman, R. and Earl, G. (in press) Experiencing Lustre: Polynomial Texture Mapping of Medieval Pottery at The Fitzwilliam Museum. Proceedings of ICAANE 2010.

Brown, B., Toler-Franklin, C., Nehab, D., Burns, M., Vlachopoulos, A., Doumas, C., Dobkin, D., Rusinkiewicz, S. and Weyrich, T. (2008) A System for High-Volume Acquisition and Matching of Fresco Fragments: Reassembling Theran Wall Paintings. ACM Transactions on Graphics (Proc. SIGGRAPH 2008), Los Angeles, CA.

Cupitt, J. and Martinez, K. (1996) "VIPS: An Image Processing System for Large Images", in: Conference Proceedings, IS\&T/SPIE Symposium. Electronic Imaging: Science and Technology, 2663, Very High Resolution and Quality Imaging, 19-28.

Dellepiane, M., Corsini, M., Callieri, M. and Scopigno, R. (2006) High quality PTM acquisition: Reflection Transformation Imaging for large objects in: Ioannides, M., Arnold, D., Niccolucci, F., Mania, K. (Eds.) VAST06: Proceedings of the $7^{\text {th }}$ 
International Symposium on Virtual Reality, Archaeology and Cultural Heritage (Cyprus, 2006), pp. 179-86.

Di Benedetto, M., Ponchio, F., Ganovelli, F. and Scopigno, R. (2010) SpiderGL: a JavaScript 3D graphics library for next-generation WWW. In Proceedings of the 15th International Conference on Web 3D Technology pp.165-174 ACM, New York.

Drew, M., Hajari, N., Hel-Or, Y. and Malzbender, T. (2009) Specularity and Shadow Interpolation via Robust Polynomial Texture Maps in: Proceedings of the British Machine Vision Conference.

Earl, G.P., Martinez, K. and Malzbender, T. (2010a) Archaeological Applications of Polynomial Texture Mapping: Analysis, Conservation and Representation. Journal of Archaeological Science 37 (2010) 2040-50.

Earl, G.P., Beale, G., Martinez, K. and Pagi, H. (2010b) Polynomial texture mapping and related imaging technologies for the recording, analysis and presentation of archaeological materials. In, ISPRS Commission V Midterm Symposium, Newcastle, UK.

Earl, G.P., Beale, G., Happa, J., Williams, M., Turley, G., Martinez, K. and Chalmers, A. (2009) A Repainted Amazon. In Proceedings of the EVA London Conference. Hampton Hill, UK, EVA Conferences International.

Hel-Or, Y., Malzbender, T. and Gelb, D. (2003) Synthesis and Rendering of 3D Textures. In Proceedings of Texture 2003 - 3rd International Workshop on Texture Analysis and Synthesis, Nice, France · October 17, 2003.

Malzbender, T., Gelb, D., Wolters, H. and Zuckerman, B. (2000) Enhancement of Shape Perception by Surface Reflectance Transformation. Tech. Rep. HPL- 2000-38R1, Hewlett-Packard Laboratories, Palo Alto, California.

Malzbender, T., Gelb, D. and Wolters, H. (2001) Polynomial Texture Maps. In SIGGRAPH "01: Proceedings of the 28th annual conference on Computer graphics and interactive techniques (New York, NY, USA), ACM Press, pp. 519-528.

Martinez, K. and Cupitt, J. (2005) VIPS - a Highly Tuned Image Processing Software Architecture, in: Conference Proceedings, IEEE International Conference on Image Processing 2, 574-577, Genova.
Mudge, M., Schroer, C., Earl, G., Martinez, K., Pagi, H., Toler-Franklin, C., Rusinkiewicz, S., Palma, G., Wachowiak, M., Ashley, M., Matthews, N., Noble, T. and Dellepiane, M. (2010) Principles and Practices of Robust, Photography-based Digital Imaging Techniques for Museums. In Artusi, A., Joly, M., Pitzalis, D., Lucet, G. and A. Ribes (Eds.) Proceedings of the 11th International Symposium on Virtual Reality, Archaeology and Cultural Heritage VAST.

Mudge, M., Malzbender, T., Chalmers, A., Scopigno, R., Davis, J., Wang, O., Gunawardane, P., Ashley, M., Doerr, M., Proenca, A. and Barbosa, J. (2008) Image-Based Empirical Information Acquisition, Scientific Reliability, and Long-Term Digital Preservation for the Natural Sciences and Cultural Heritage. Eurographics.

Mudge, M., Malzbender, T., Schroer, C. and Lum, M. (2006) New Reflection Transformation Imaging Methods for Rock Art and Multiple-Viewpoint Display. In M. loannides, D. Arnold, F. Niccolucci, (Eds.) Proceedings of the7th International Symposium on Virtual Reality, Archaeology and Cultural Heritage (VAST2006), Eurographics Association, pp. 195-200.

Mudge, M., Voutaz, J. P., Schroer, C. and Lum, M. (2005) Reflection Transformation Imaging and Virtual Representations of Coins from the Hospice of the Grand St. Bernard. In Mudge, M., Ryan, N., Scopigno R. (Eds.) Proceedings of 6th International Symposium on Virtual Reality, Archaeology and Cultural Heritage (VAST2005), Eurographics Association, pp. 29-39.

Piquette, K. E. (Forthcoming) "It is Written?: Making, remaking and unmaking early 'writing' in the lower Nile Valley." In Piquette, K. E. and Whitehouse, R. D. (Eds.) Writing as Material Practice: Substance, surface and medium. New York: Cambria Press.

RTIViewer. http://www.c-h-

i.org/learn/learn RTIviewer download.html (retrieved 25 April 2011)

Toler-Franklin, C., Finkelstein, A. and Rusinkiewicz, S. (2007) Illustration of Complex Real-World Objects using Images with Normals. In International Symposium on Non-Photorealistic Animation and Rendering (NPAR).

Woodham, R. (1980) Photometric method for determining surface orientation from multiple images. Optical Engineering, 19(1), pp. 139-144. 